\title{
CORRECTION \\ Correction: Similarities and differences in spatial and non-spatial cognitive maps
}

\author{
Charley M. Wu, Eric Schulz, Mona M. Garvert, Björn Meder, Nicolas W. Schuck
}

The funding statement for this article should read as follows:

"NWS was funded by an Independent Max Planck Research Group grant awarded by the Max Planck Society and a Starting Grant from the European Union (ERC-2019-StG-REPLAY852669). ES is supported by the Max Planck Society and the Jacobs Foundation. The funders had no role in study design, data collection and analysis, decision to publish, or preparation of the manuscript."

\section{Reference}

1. Wu CM, Schulz E, Garvert MM, Meder B, Schuck NW (2020) Similarities and differences in spatial and non-spatial cognitive maps. PLoS Comput Biol 16(9): e1008149. https://doi.org/10.1371/journal.pcbi. 1008149 PMID: 32903264

\section{fopenaccess}

Citation: Wu CM, Schulz E, Garvert MM, Meder B, Schuck NW (2020) Correction: Similarities and differences in spatial and non-spatial cognitive maps. PLoS Comput Biol 16(10): e1008384. https://doi.org/10.1371/journal.pcbi.1008384

Published: October 21, 2020

Copyright: ๑ 2020 Wu et al. This is an open access article distributed under the terms of the Creative Commons Attribution License, which permits unrestricted use, distribution, and reproduction in any medium, provided the original author and source are credited. 